\title{
ANALISA PERANCANGAN DESAIN APLIKASI PENGELOLAAN ABSENSI DAN SISTEM PENGGAJIAN KARYAWAN PADA DAIHATSU CAPELLA MEDAN CABANG PADANG
}

\author{
Tito, Redha Ramadhani, Annisak Izzaty Jamhur \\ Universitas Indonesia "YPTK” Padang, Indonesia \\ Email: rereramadhani31@gmail.com
}

\begin{abstract}
The payroll system is one of the things related to the management of the welfare of the workforce so it must be given special attention by the company in order to achieve its objectives. Salary has a very important meaning for employees because salary is a reflection of the value of the work, and also as an encouragement in a job of their performance, both for the company, the community, and for themselves. In the form of a company's payroll system, employee absence is very influential in taking employee salaries. As in the field research, it can be taken from Daihatsu Capella Medan, Padang Branch. This PT is a company that already exists in several regions in Indonesia
\end{abstract}

Keywords:: Payroll System, Salary, Daihatsu Capella Medan Padang Branch

\begin{abstract}
Abstrak
Sistem penggajian adalah salah satu hal yang berkaitan dengan pengelolaan kesejahteraan tenaga kerja sehingga harus diberi perhatian khusus oleh perusahaan dalam rangka mencapai tujuannya. Gaji memiliki arti yang sangat penting bagi karyawan karena gaji merupakan cerminan nilai atas karya, dan juga sebagai penyemangat dalam sebuah pekejaan dari kinerja mereka, baik bagi perusahaan, masyarakat, maupun bagi diri mereka sendiri. Dalam bentuk sistem penggajian sebuah perusahaan, absensi karyawan sangatlah berpengaruh dalam pengambilan gaji karyawan. Seperti halnya dalam penelitian lapangan dapat diambil dari Daihatsu Capella Medan Cabang Padang. PT ini merupakan sebuah perusahaan yang sudah ada di beberapa daerah di Indonesia
\end{abstract}

Kata kunci: : Sistem Penggajian, Gaji, Daihatsu Capella Medan Cabang Padang

\section{Pendahuluan}

Kemajuan teknologi dan informasi pada sekarang ini berkembang demikian pesat. Hal tersebut salah satunya ditandai dengan penerapan sistem pelayanan yang serba terkomputerisasi di sejumlah instansi seperti Perusahaan, Perkantoran, dan lain-lain dalam memberikan pelayanan kepada masyarakat. Sistem penggajian adalah salah satu hal yang berkaitan dengan pengelolaan kesejahteraan tenaga kerja sehingga harus diberi perhatian khusus oleh perusahaan dalam rangka mencapai tujuannya. Gaji memiliki arti yang sangat penting bagi karyawan karena gaji merupakan cerminan nilai atas karya, dan juga sebagai penyemangat dalam sebuah pekejaan dari kinerja mereka, baik bagi perusahaan, masyarakat, maupun bagi diri mereka sendiri. Dalam bentuk sistem penggajian sebuah perusahaan, absensi karyawan sangatlah berpengaruh dalam pengambilan gaji karyawan. Seperti halnya dalam penelitian lapangan dapat diambil dari Daihatsu Capella Medan Cabang Padang. PT ini merupakan sebuah perusahaan yang sudah ada di beberapa daerah di Indonesia. Dilihat dari bentuk sistem penggajian PT ini belum memenuhi standar komputerisasi, ini dapat dilihat dalam pengambilan absensinya yang masih menggunakan sistem manual dan masih belum menggunakan standar komputerisasinya. Sistem penggajian di Daihatsu Capella Medan Cabang Padang masih rentan terhadap berbagai bentuk kesalahan teknis dari manusia, ketidaktepatan penggajian dan juga penitipan absen juga menyebabkan kurang efektifnya perusahaan belum memenuhi standar komputerisasi. Terkait dengan kelemahan dan 
keterbatasan sistem Absensi secara manual seperti yang diterapkan di Daihatsu Capella Medan Cabang Padang, bisa menyebabkan kekacauan pada penerimaan gaji karyawan, seperti adanya keterlambatan dan tidak tepat waktu dalam penggajian. Sistem penggajian terkomputerisasi diperlukan untuk meningkatkan pelayanan khususnya berkaitan dengan penggajian karyawan. Dengan penerapan sistem absensi dan penggajian terkomputerisasi, sistem penggajian menjadi terorganisir dengan baik dan benar, waktu yang dibutuhkan menjadi lebih efektif dan efisien, serta dimungkinkannya seluruh data tersimpan dengan baik, sehingga dapat mempermudah kegiatan penggajian di perusahaan.

\section{Metode Penelitian}

\subsection{Kerangka Penelitian}

Kerangka penelitian merupakan konsep atau tahapan-tahapan yang akan dilakukan dalam penelitian. Agar langkah-langkah yang diambil penulis dalam perancangan ini tidak melenceng dari pokok pembahasan dan lebih mudah dipahami, maka urutan langkah-langkah penelitian akan dibuat secara sistematis sehingga dapat dijadikan pedoman yang jelas dan mudah untuk menyelesaikan permasalahan yang ada. Adapun kerangka penelitian yang penulis lakukan dalam penelitian yang akan diuraikan pada Gambar 2.1 berikut ini:

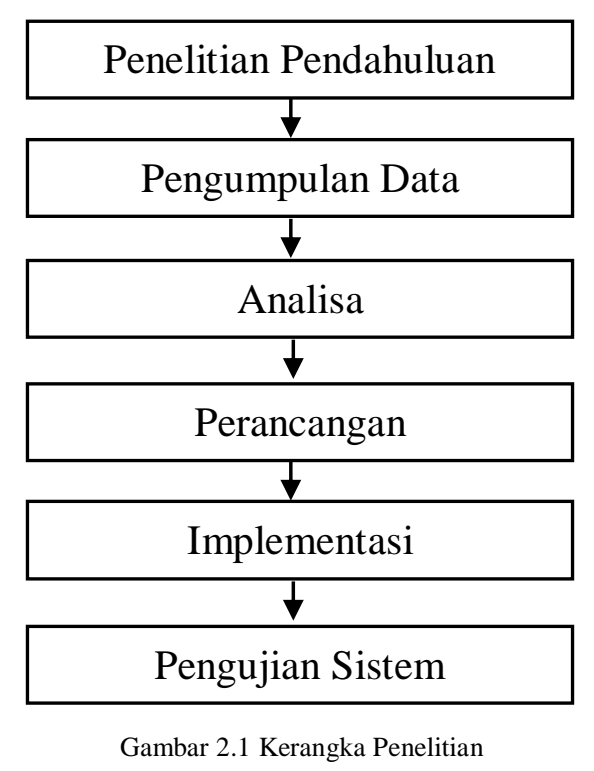

\subsection{Tahapan Peneletian}

Dalam Penelitian ini terdapat beberapa tahapan yang akan dilakukan agar penelitian dapat dilakukan dengan baik. Adapun penelitian tentang tahapan-tahapan penelitian dalam gambar 2.1 Kerangka Penelitian adalah sebagi berikut.

\subsubsection{Penelitian Pendahuluan}

Penelitian pendahuluan adalah langkah awal dalam melakukan penelitian. Dalam tahap ini berisi latar belakang, ruang lingkup penelitian dan manfaat penulisan, tujuan umum perusahaan, sejarah perusahaan, struktur organisasi, beserta deskripsi tugas masing-masing bagian dalam perusahaan dan mengidentifikasi permasalahan yang ada. Dengan penelitian pendahuluan dapat memberikan bukti awal bahwa masalah yang akan kita teliti di lapangan benar-benar ada. Penelitian ini dilakukan dengan cara survey kelapangan dan servey data sebelum melakukan penelitian lebih lanjut terhadap objek penelitian. Oleh sebab itu 
dibutuhkan waktu untuk pengambilan data, waktu penelitian, tempat penelitian, metode penelitian, penelitian lapangan, riset perpustakaan, dan penelitian labor.

\subsubsection{Pengumpulan Data}

Pengumpulan data dilakukan dengan mempelajari buku-buku, jurnal, dan tulisan yang berhubungan dengan penelitian ini. Dalam pengumpulan data dilakukan dengan cara mewawancarai dengan pihak Dihatsu Capella Medan Cabang Padang, agar penelitian menhasilkan sebuah data yang optimal.

\subsubsection{Analisa}

Untuk melakukan penelitian, penulis melakukan analisa terhadap data-data yang telah dikumpulkan serta menganalisa sistem yang akan dijalankan sebagai solusi dari perumusan masalah yang didapat. Yaitu : Pertama Analisis data, Tahap analisa data merupakan tahap yang sangat penting dalam pengembangan sebuah sistem, karena pada tahap inilah yang nantinya akan dilakukan evaluasi kerja. Analisa data dilakukan untuk mendapatkan fakta-fakta berdasarkan metode yang digunakan dalam penelitian, data yang diperoleh dari pihak Daihatsu Capella akan dianalisa sehingga mendapatkan data yang akurat. Kedua Analisis Proses, Pada tahap analisa proses ini, penulis akan merancang sebuah sistem absensi dan penggajian. Dimana sistem tersebut diaharapkan dapat menjadi solusi yang tepat untuk unutk membantu pengolahan data pada Daihatsu Capella. Dan yang ketiga Analisis system, Pada tahap analisis sistem ini merupakan tahapan yang sangat kritis dan sangat penting, karena kesalahan pada tahapan analisis sistem akan menyebabkan juga kesalahan ditahap selanjutnya. Tahap analisis sistem meruapakan dasar dalam merancang dan merencanakan sistem yang akan dibuat, analisa sistem dilakukan untuk mengetahui apa saja yang dibutuhkan oleh sistem. Analisis sistem ini dilakukan untuk merancang sistem yang meliputi perancangan tampilan user, merancang basisdata untuk sistem tersebut agar manajemen file lebih teratur. Dimana sistem yang akan dibuat mengunakan bahasa pemrograman PHP dan database MySQL.

\subsubsection{Perancangan}

Tahapan perancangan ini, peneliti mengunakan Unified Modeling Language (UML) sebagai tools dalam menjelaskan alur analisa yang akan dibuat, dimana UML yang digunakan yaitu : Use Case Diagram, Class Diagram, Activity Diagram, Sequence Diagram.

\subsubsection{Implementasi}

Tahapan implementasi sistem merupakan tahapan memasukkan data-data yang telah diolah dan menerapkan model yang baik sehingga data tersebut siap dioperasikan. Dalam penelitian ini penulis merancang dan membangun sistem informasi, untuk mengimplementasikan sistem yang telah dirancang maka diperlukan sebuah alat bantu komputer untuk mengoperasikan sistem tersebut. Untuk mengoperasikan komputer juga diperlukan komponen pendukung seperti hardware, software, dan brainware.

\subsubsection{Pengujian Sistem}

Pengujian merupakan tahapan penelitian yang dilakukan untuk mempraktekkan langsung hasil dari analisa yang bertujuan untuk menguji kebenaran sistem yang dirancan Implementasi ini juga akan menjelaskan bagaimana cara menggunkan sistem informasi penggajian dan absensi pada Daihatsu Capella Medan Cabang Padang. Untuk lebih jelasnya menegenai implementasi ini akan dijelaskan pada bab V dalam laporan penelitian.

\section{Hasil dan Pembahasan}

Analisa sistem dapat didefinisikan sebagai penguraian dari suatu sistem informasi yang utuh kedalam bagian bagian komponennya dengan maksud untuk mengindentifikasi dan mengevaluasi permasalahan-permasalahan, kesempatan, hambatan, dan kebutuhan- kebutuhan yang diharapkan sehingga dapat diusulkan perbaikan- perbaikannya. Analisa sistem dapat didefinisikan sebagai penguraian dari suatu sistem informasi yang utuh kedalam bagian bagian komponennya dengan 
maksud untuk mengindentifikasi dan mengevaluasi permasalahan-permasalahan, kesempatan, hambatan, dan kebutuhan- kebutuhan yang diharapkan sehingga dapat diusulkan perbaikanperbaikannya. Dari hasil penelitian yang telah dilakukan baik dengan melakukan survey langsung ke Daihatsu Capella Medan Cabang Padang maupun tidak langsung, maka dapat diuraikan kerja sistem yang ada Daihatsu Capella Medan Cabang Padang. Dimana dalam pengolahan data, Daihatsu Capella Medan Cabang Padang membutuhkan waktu yang lama dan kurang efisien karena masih belum optimalnya penggunaan komputerisasi dan analisa yang dilakukan secara manual.

\subsection{Evaluasi Sistem Yang Sedang Berjalan}

Tahapan alias sistem dilakukan sebelum tahap perancangan sistem. Tahapan alias sistem merupakan tahap yang terpenting dalam perancangan suatu sistem. Tujuan analisa terhadap sistem yang lama ini adalah untuk mendapatkan hasil yang lebih baik dengan melihat beberapa kelemahan dan kekurangan dari sistem yang lama.Sebelum melakukan perancangan terhadap sistem yang baru, perlu adanya gambaran mengenai sistem yang ada atau sistem yang sedang berjalan pada Daihatsu Capella Medan Cabang Padang, hal ini untuk memudahkan dalam melakukan perancangan sistem, sehingga apa yang diinginkan akan berjalan dengan baik. Daihatsu Capella Medan Cabang Padang dalam pengolahan data absensi dan penggajian karyawan masih menggunakan proses manual dan juga dalam penyajian laporan sering ketidaksamaan hasil yang didapat dengan hasil laporannya. Dan juga dalam penyajian laporan membutuhkan waktu yang lama, sehingga sulit pimpinan dalam mengambil keputusan.

\subsection{Desain Sistem Baru}

Berdasarkan identifikasi masalah yang ada pada bab sebelumnya maka ditemui kelemahan pada sistem yang lama, antara lain:Belum adanya aplikasi yang bisa dipergunakan untuk melakukan sistem absensi karyawan pada Daihatsu Capella Medan Cabang Padang. Tidak adanya aplikasi yang menampilkan data gaji karyawan pada Daihatsu Capella Medan Cabang Padang.Untuk mengatasi masalah-masalah yang ada, diperlukan perancangan sistem baru untuk mendefenisikan kebutuhan fungsional. Sistem baru dibangun untuk memudahkan proses pengolahan data sehingga tidak lagi memerlukan waktu yang lama dan diusulkan untuk disajikan dalam bentuk rancangan fisik dan rancangan logika. Sistem yang diusulkan diharapkan dapat melakukan perbaikan terhadap kekurangan yang ada pada sistem yang lama

\subsection{Use Case Diagram}

Use case diagram menjelaskan manfaat dari aplikasi jika dilihat dari sudut pandang orang yang berada diluar sistem (aktor). Diagram ini menunjukkan fungsionalitas suatu sistem atau kelas dan bagaimana sistem berinteraksi dengan dunia luar. Use case diagram dapat digunakan selama proses analisa untuk menangkap requirements atau permintaan terhadap sistem dan untuk memahami bagaimana sistem tersebut harus bekerja. Adapun Use Case Diagram sistem informasi Daihatsu Capella pada Kota Padang dapat digambarkan seperti Gambar 3.1. 


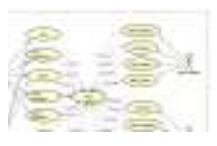

Gambar 3.1 Use Case Diagram

\subsection{Class Diagram}

Class diagram adalah sebuah spesifikasi yang jika diinstansiasi akan menghasilkan sebuah objek dan merupakan inti dari pengembangan dan desain berorientasi objek. Adapun Class Diagram sistem informasi Daihatsu Capella Medan Cabang Padang dapat digambarkan seperti Gambar 3.2.

3.5 Pengujian Program

Pada bagian pengujian program ini akan dijelaskan mengenai penggunaan dari aplikasi yang dibuat. Penjelasan aplikasi yang dibuat meliputi tampilan aplikasi, fungsi kontrol dalam aplikasi, serta cara penggunaanya. Pada sub bab akan dijelaskan tentang penggunaan aplikasi per sistem menu, mulai dari tampilan menu utama, fungsi dan cara penggunaannya sampai selesai.

\section{Halaman Login}

Form Login merupakan form untuk masuk sebagai Pimpinan, Karyawan, Bagian Karyawan dan Bagian Gaji dimana semuanya masuk sesuai dengan kapasitasnya. Bentuk form login seperti pada gambar 3.3 berikut ini : 


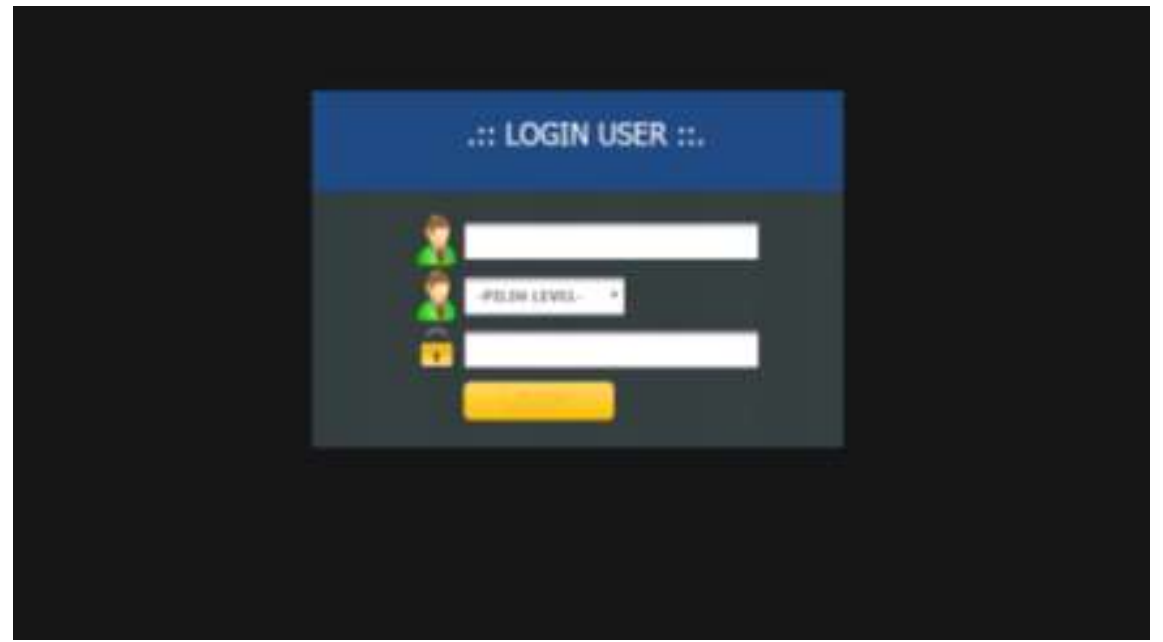

Gambar 3.3 Halaman Login

\section{Halaman Awal Karyawan}

Halaman Awal Karyawan berisikan menu-menu untuk karyawan, lebih jelas dapat dilihat pada Gambar 3.4 berikut :

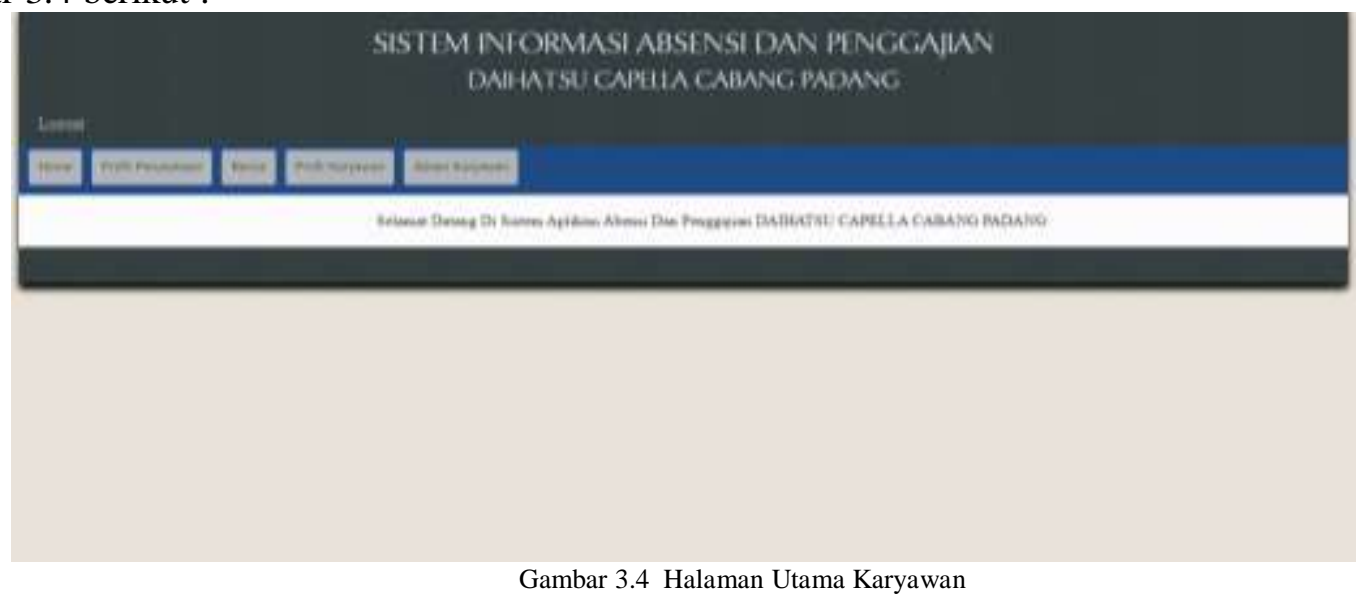

\section{Halaman Profil Perusahaan}

Halaman Profil Perusahaan berisikan informasi tentang perusahaan, untuk lebih jelas dapat dilihat pada Gambar 3.5 berikut : 
MAJALAH ILMIAH UPI YPTK VOL NO 27, NO 1 HAL 45- 58 Copyright@2020 LPPM UPI YPTK

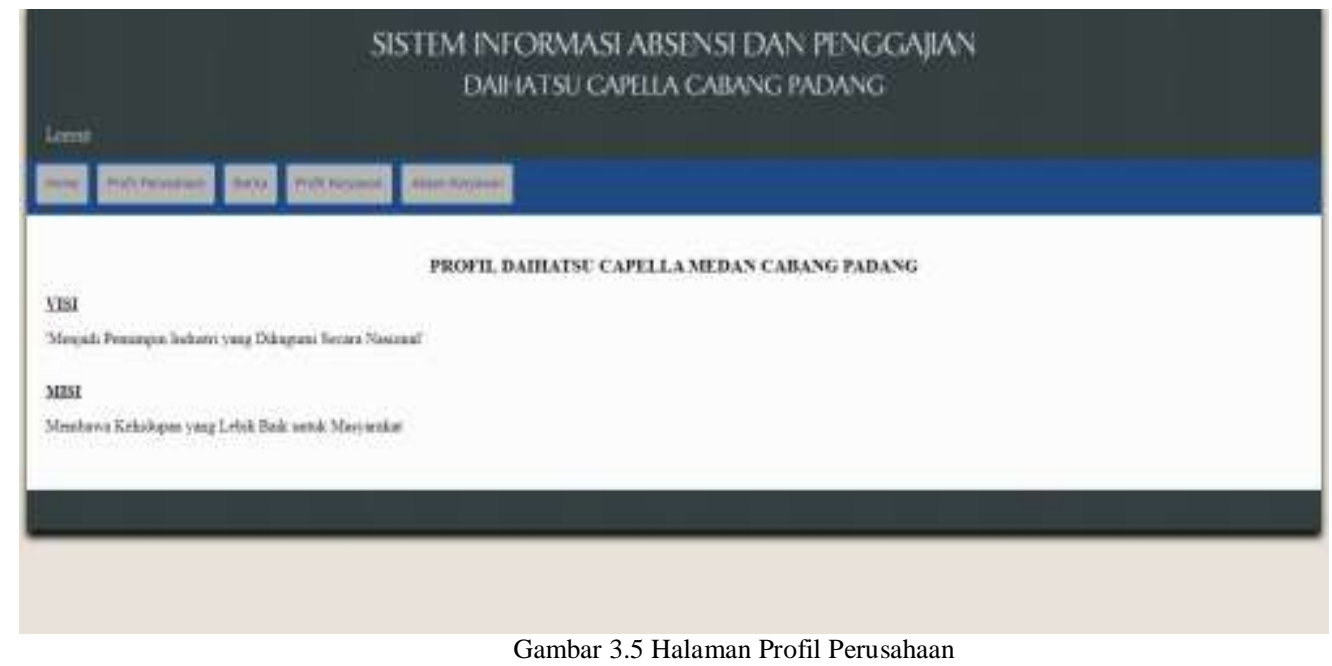

\section{Halaman Berita}

Halaman Berita berisikan tentang berita dari perusahan yang dilihat pada pada Gambar 3.6 :

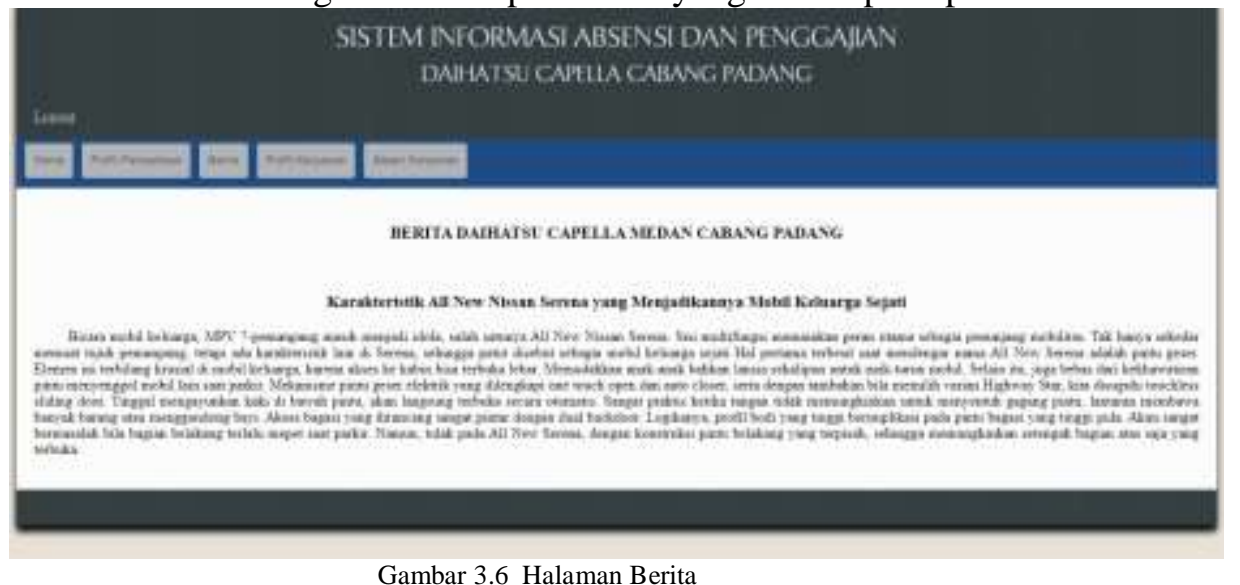

5. Halaman Profil Karyawan

Gambar 3.6 Halaman Berita

Halaman Profil Karyawan berisikan informasi tentang karyawan, Tampilannya dapat dilihat pada Gambar 3.7 berikut :
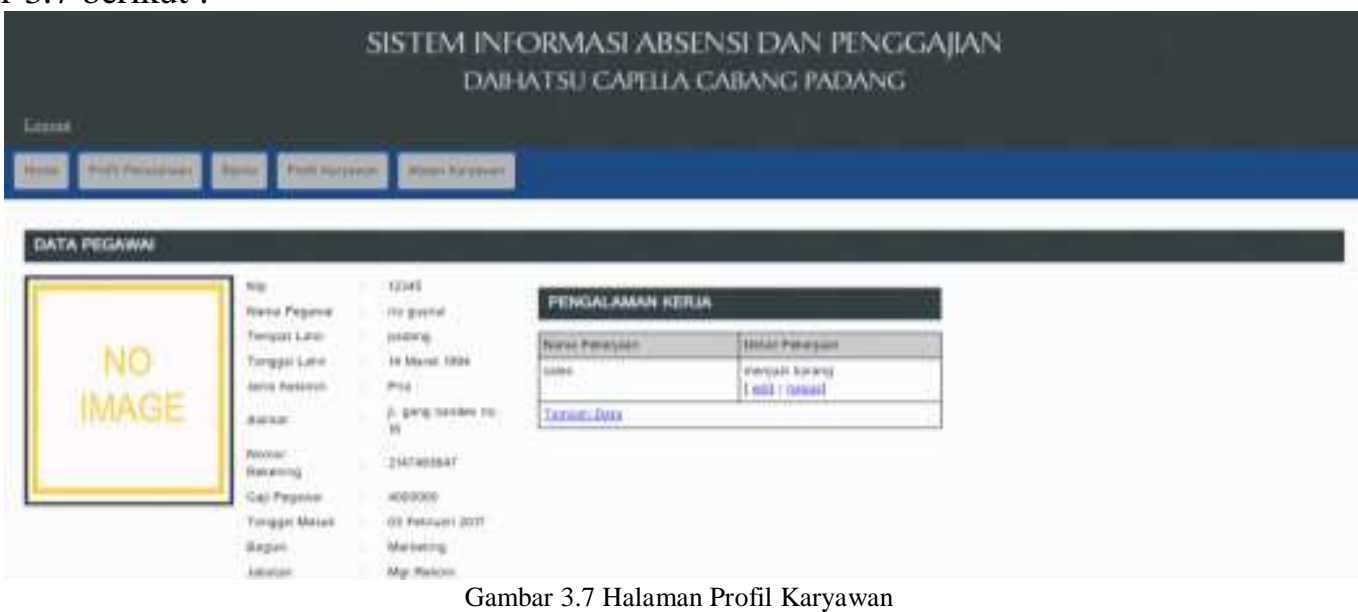

\section{Halaman Absen Karyawan}

Halaman Absen Karyawan digunakan oleh karyawan mengisi absen setiap harinya. Tampilannya dapat dilihat pada gambar 3.8 berikut ini : 
MAJALAH ILMIAH UPI YPTK VOL NO 27, NO 1 HAL 45- 58 Copyright@2020 LPPM UPI YPTK

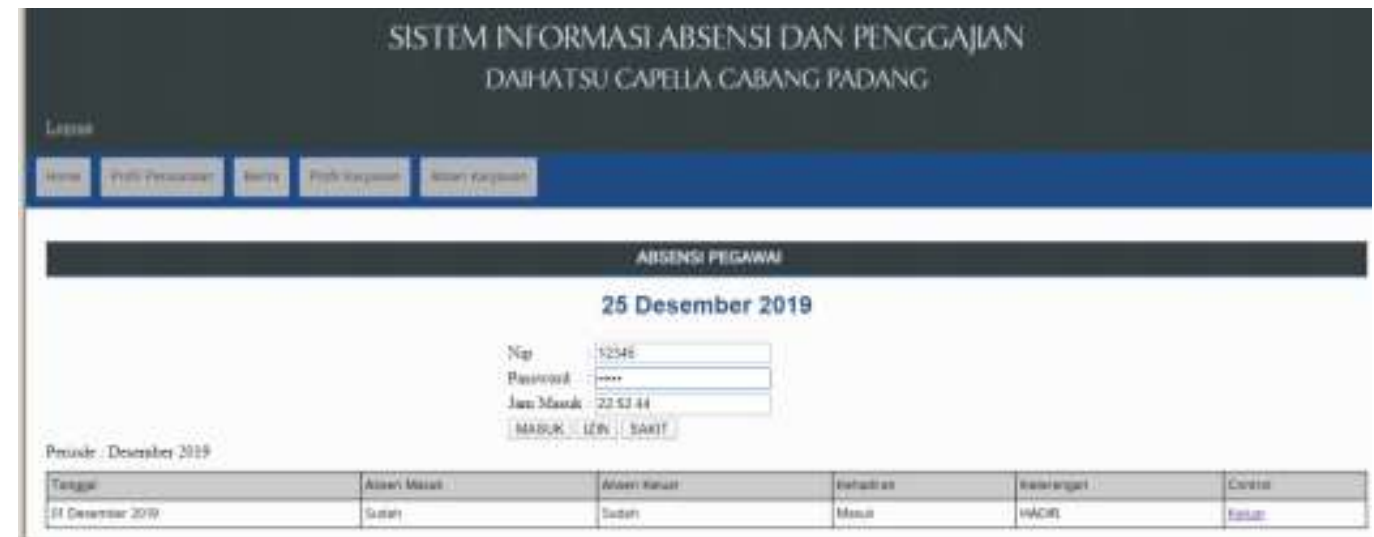

Gambar 3.8 Halaman Absen Karyawan

7. Halaman Awal Pimpinan

Halaman Pimpinan berisikan menu-menu untuk pimpinan, lebih jelas dapat dilihat pada Gambar 3.9. berikut :

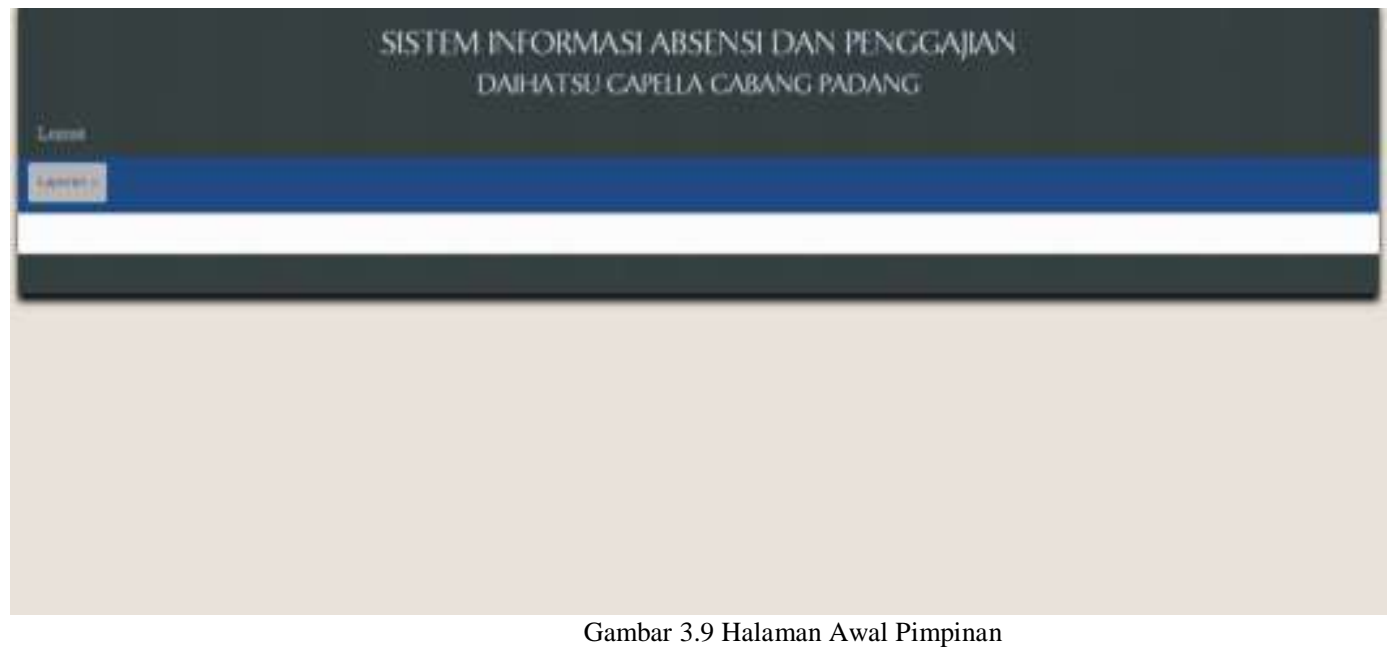

8. Halaman Laporan Data Pegawai

Gambar 3.9 Halaman Awal Pimpinan

Halaman Laporan Data Pegawai berisikan daftar-daftar pegawai yang dapat dilihat pada gambar 3.10. berikut ini :

\begin{tabular}{|c|c|c|c|c|c|c|}
\hline \multicolumn{7}{|c|}{ WAOENA OATA FESAWWN } \\
\hline Ais & 8 & tum frams & Fruse titus & incomen & ines & tran \\
\hline 1 & tais & Sira Ravenuas: & Wintab 306 & Frimen: & Wy flewin: & Drietfruast \\
\hline 2 & tases & sones & a fwenas 200 & COE: & Wy hemen & Deut buanal \\
\hline 3 & $\infty$ & nate & 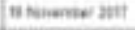 & 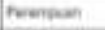 & Hyineses & |laneloveal \\
\hline
\end{tabular}

$$
\text { TCent naimum }
$$

Gambar 3.10 Halaman Laporan Data Pegawai

\section{Halaman Absensi}

Halaman Absensi berisikan penentuan absen per periode dapat dilihat pada gambar 3.11 berikut ini : 
MAJALAH ILMIAH UPI YPTK VOL NO 27, NO 1 HAL 45- 58 Copyright@2020 LPPM UPI YPTK

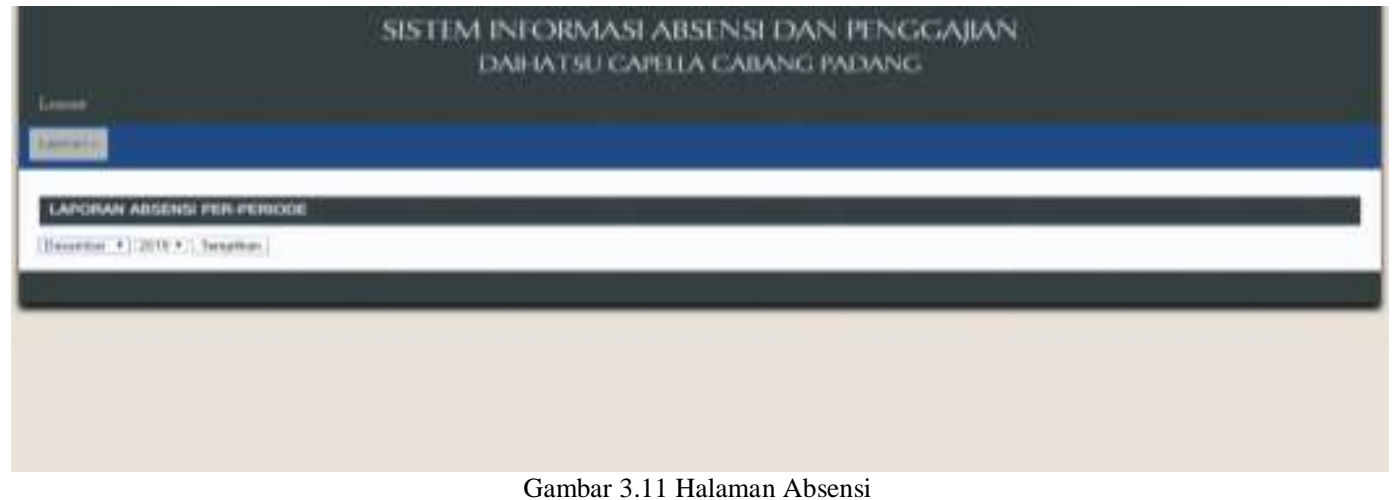

\section{Halaman Laporan Absensi}

Halaman Laporan Absensi berisikan daftar-daftar absen karyawan yang dapat dilihat pada gambar 3.12 berikut ini :

\begin{tabular}{|c|c|c|c|c|c|c|c|}
\hline \multirow{2}{*}{ ne } & \multirow{2}{*}{ kq } & \multirow{2}{*}{ nate Promo } & \multirow{2}{*}{ Bogar } & \multirow{2}{*}{ neomen } & \multicolumn{2}{|c|}{ 7nteriedr } & \multirow{2}{*}{ Tranter } \\
\hline & & & & & tan & Sase & \\
\hline 1 & tas & Noma nurtumats: & Menterting & a nam & o.sar. & F sait & Dom \\
\hline 2 & was & tio gavis & Meviensy & than & $9 \mathrm{cmi}$ & o vir & naw \\
\hline 3 & tow0 & taso & Mintery & to ani & lonil & 10 an & lotat \\
\hline
\end{tabular}

Cesak Halumas

Gambar 3.12 Halaman Laporan Absensi

\section{Halaman Gaji Perbulan}

Halaman Gaji berisikan penentuan gaji perbulan dapat dilihat pada gambar 3.13 berikut ini :

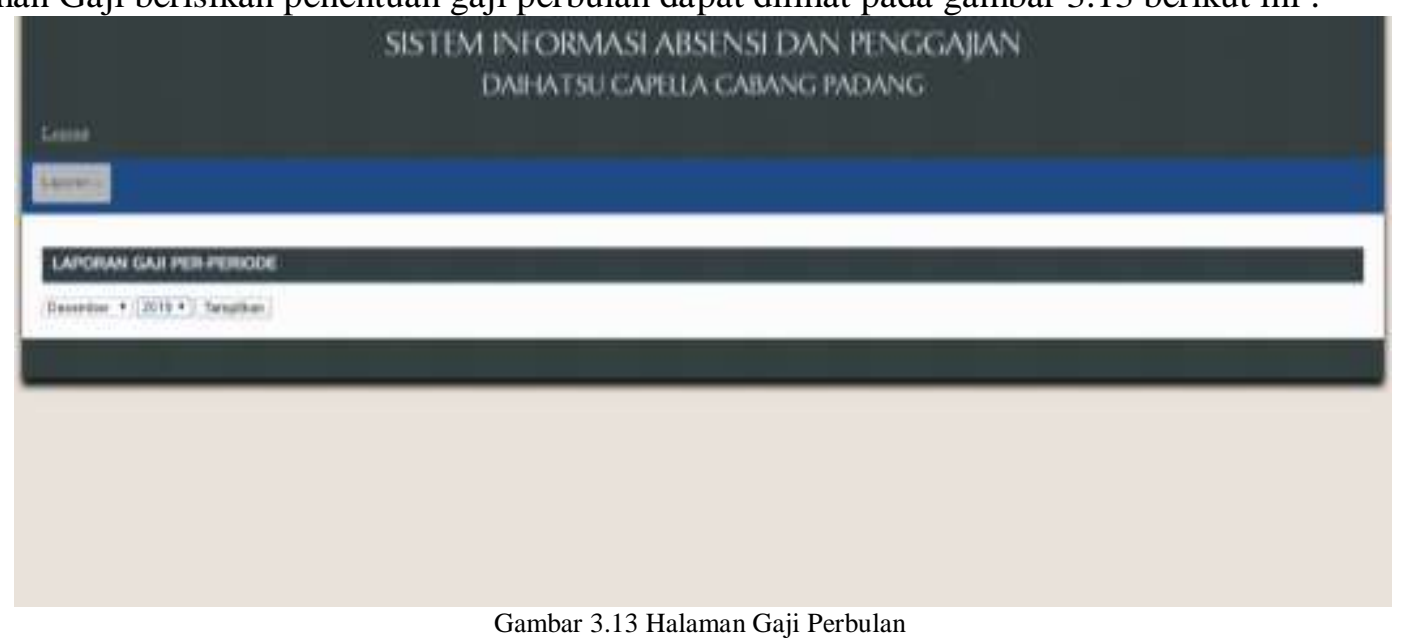

12 Halaman Laporan Gaji

Halaman Laporan Gaji berisikan daftar-daftar laporan gaji, dapat dilihat pada gambar 3.14 berikut ini :

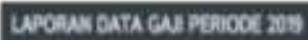

\begin{tabular}{|c|c|c|c|c|c|c|c|c|c|c|c|c|c|}
\hline$\omega$ & netu & trues & in & $\begin{array}{l}\text { Ley } \\
\text { Larar }\end{array}$ & $\begin{array}{l}\text { toverips } \\
\text { ne }\end{array}$ & $\begin{array}{l}\text { some } \\
\text { wion }\end{array}$ & $\begin{array}{l}\text { turestan } \\
\text { nimen }\end{array}$ & 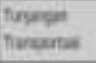 & nineyn & $\begin{array}{l}\text { pavos: } \\
\text { Les }\end{array}$ & $\begin{array}{l}\text { hoser } \\
\text { trontar }\end{array}$ & 60 & $\begin{array}{l}\text { for } \\
\text { (ati) }\end{array}$ \\
\hline 1 & ons & $\begin{array}{l}\text { meit } \\
11\end{array}$ & E & 1000 & 100000 & isoout & 20000 & 20000 & 10000 & 10000 & (1) & retowas & exteon \\
\hline
\end{tabular}

Cots Howas

Gambar 3.14 Halaman Laporan Gaji

13. Halaman Awal Bagian Pegawai 
Halaman Awal Bagian Pegawai berisikan menu-menu untuk bagian pegawai perusahaan, gambar 3.15 berikut ini :

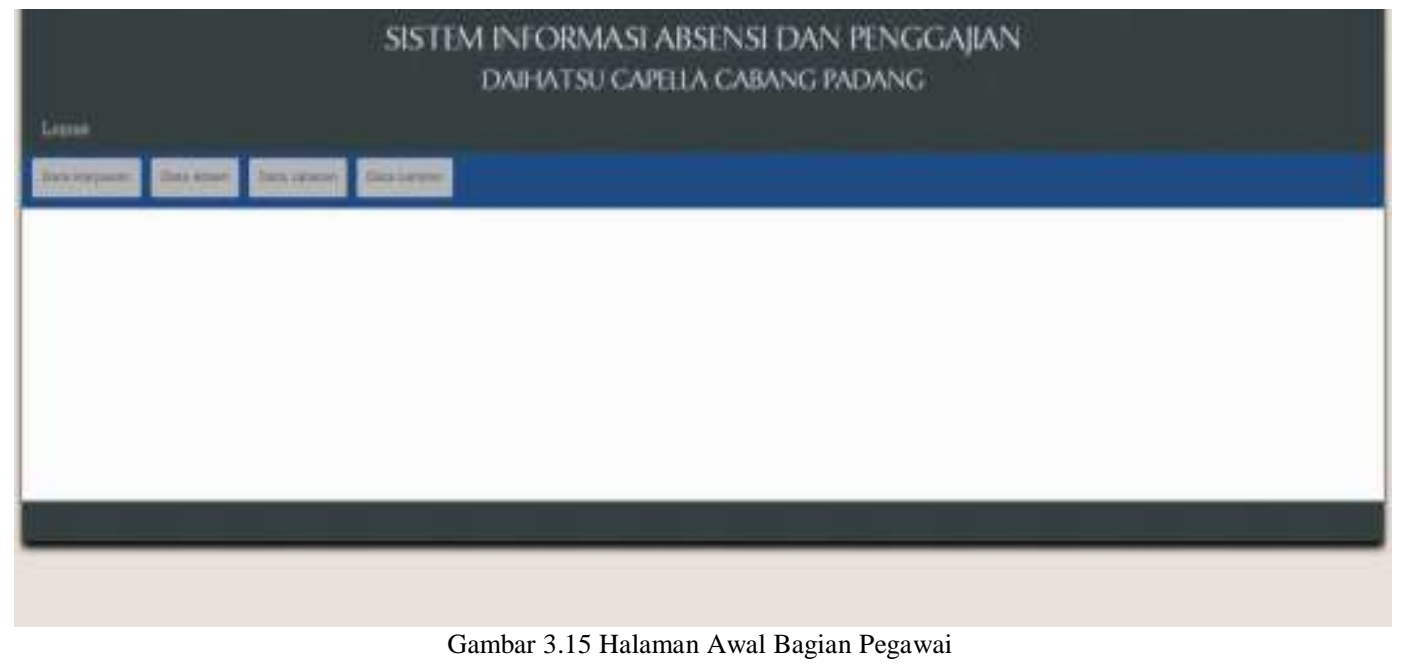

14. Halaman Data Karyawan

Halaman Data Karyawan berisikan data karyawan yang ada diperusahaan, dapat dilihat gambar 3.16 berikut ini :

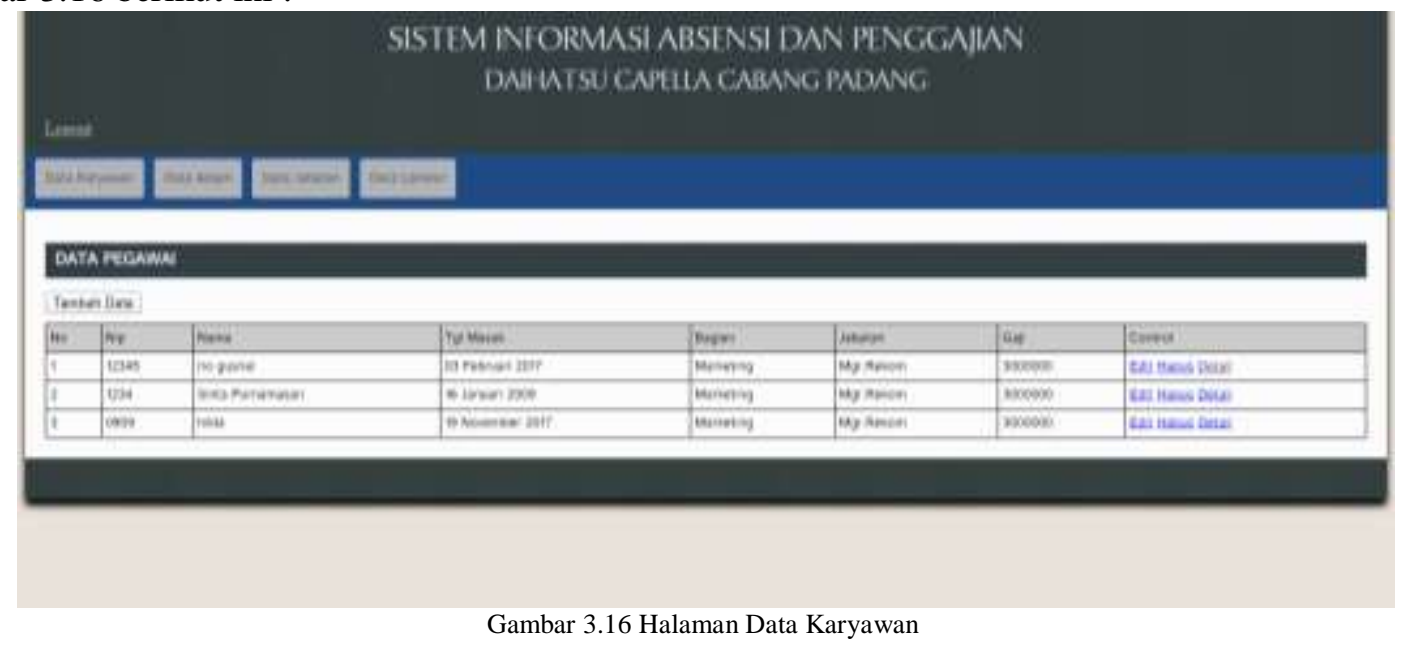

15. Halaman Data Absen

Halaman Data Absen berisikan data absen untuk karyawan, dapat dilihat gambar 3.17 berikut ini : 
MAJALAH ILMIAH UPI YPTK VOL NO 27, NO 1 HAL 45- 58

Copyright@2020 LPPM UPI YPTK

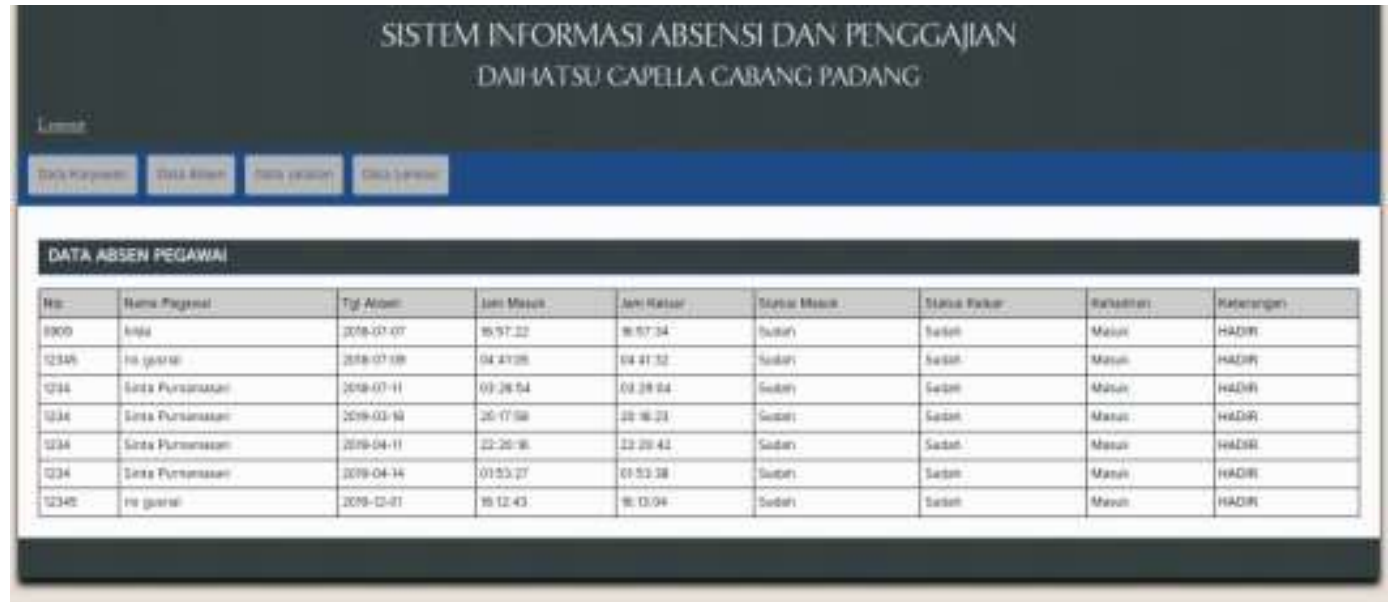

Gambar 3.17 Halaman Data Absen

16. Halaman Data Jabatan

Halaman Data Jabatan berisikan data jabatan untuk karyawan, dapat dilihat gambar 3.18 berikut ini :

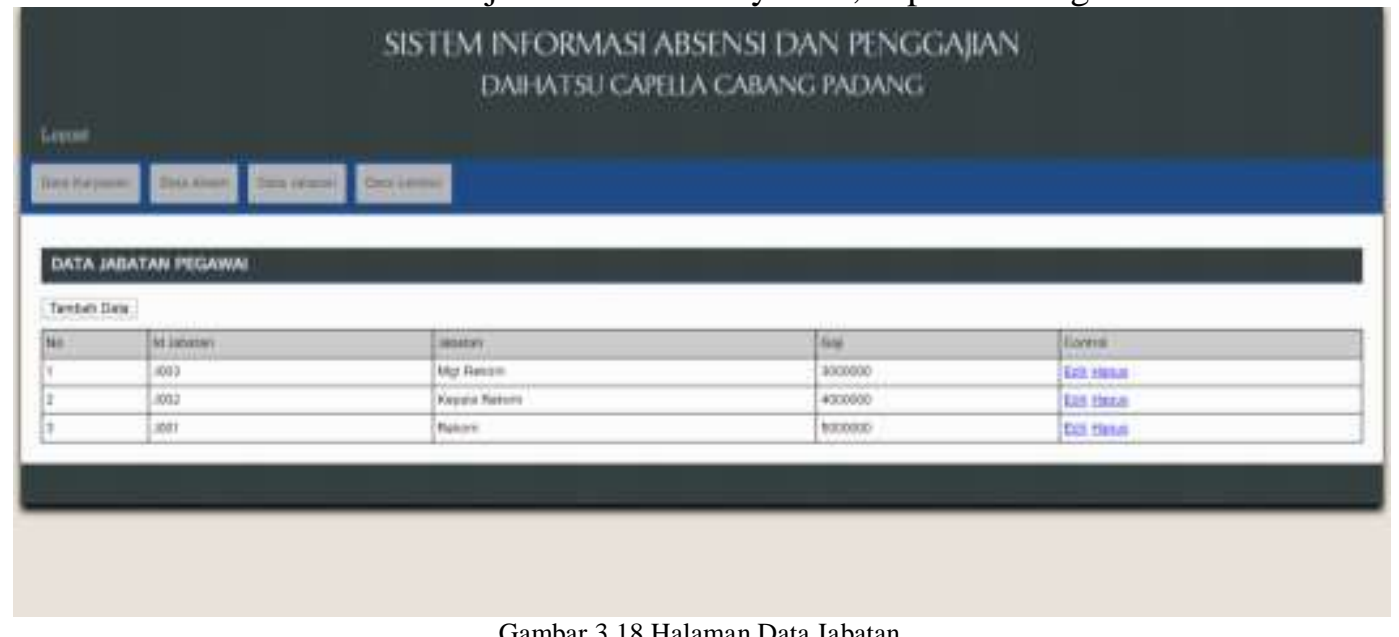

Gambar 3.18 Halaman Data Jabatan

17. Halaman Data Lembur

Halaman Data Lembur berisikan data lembur karyawan, dapat dilihat gambar 3.19 berikut ini :

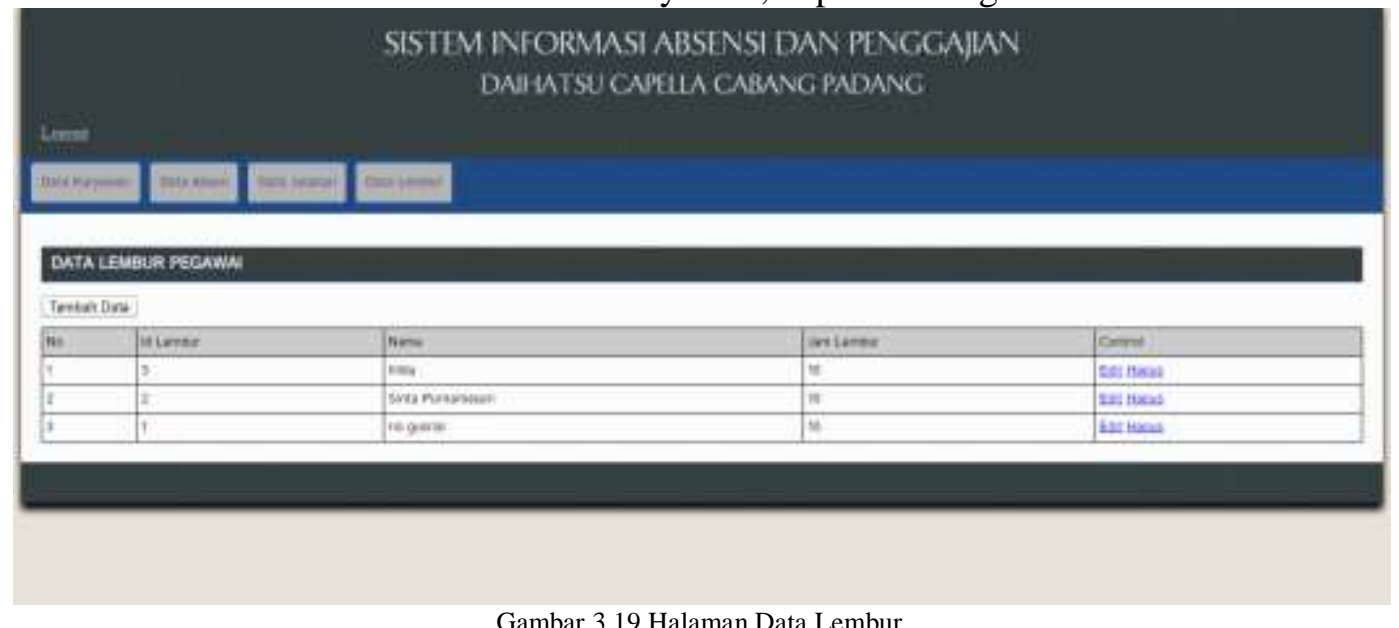

Gambar 3.19 Halaman Data Lembur

18. Halaman Data Gaji 
Halaman Data Gaji berisikan data gaji karyawan yang ada diperusahaan, dapat dilihat gambar 3.20 berikut ini :

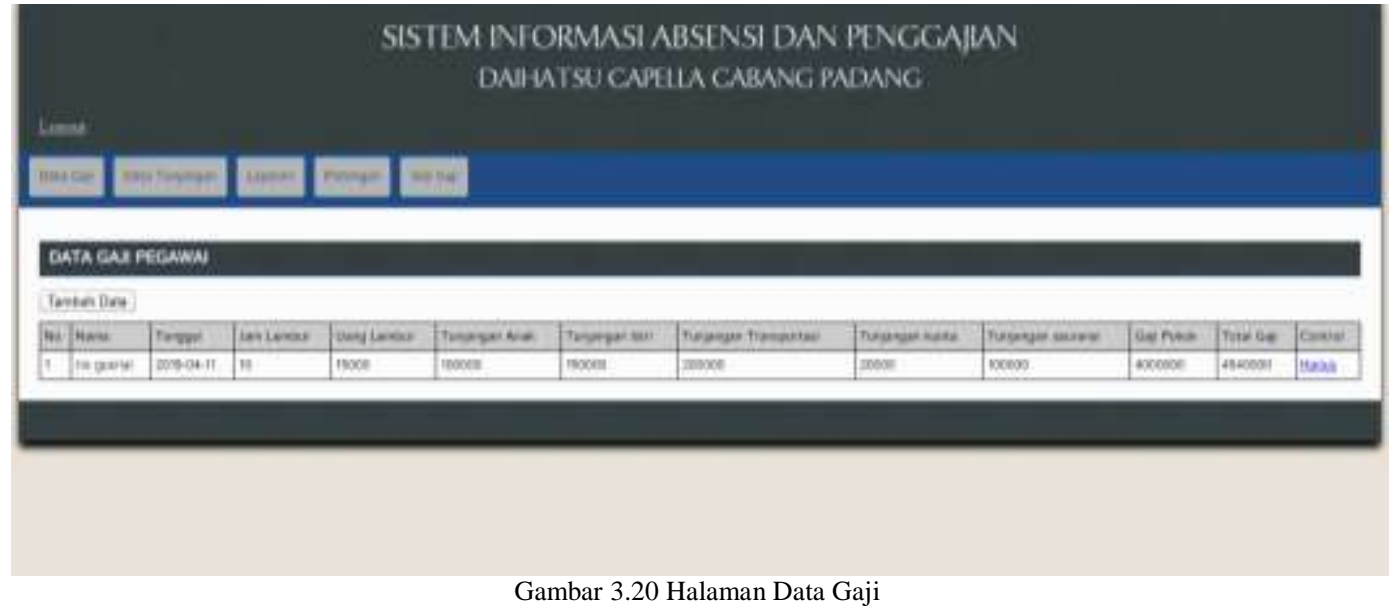

19. Halaman Data Tunjangan

Halaman Data Tunjangan berisikan data tunjangan untuk karyawan, dapat dilihat gambar 3.21 berikut ini :

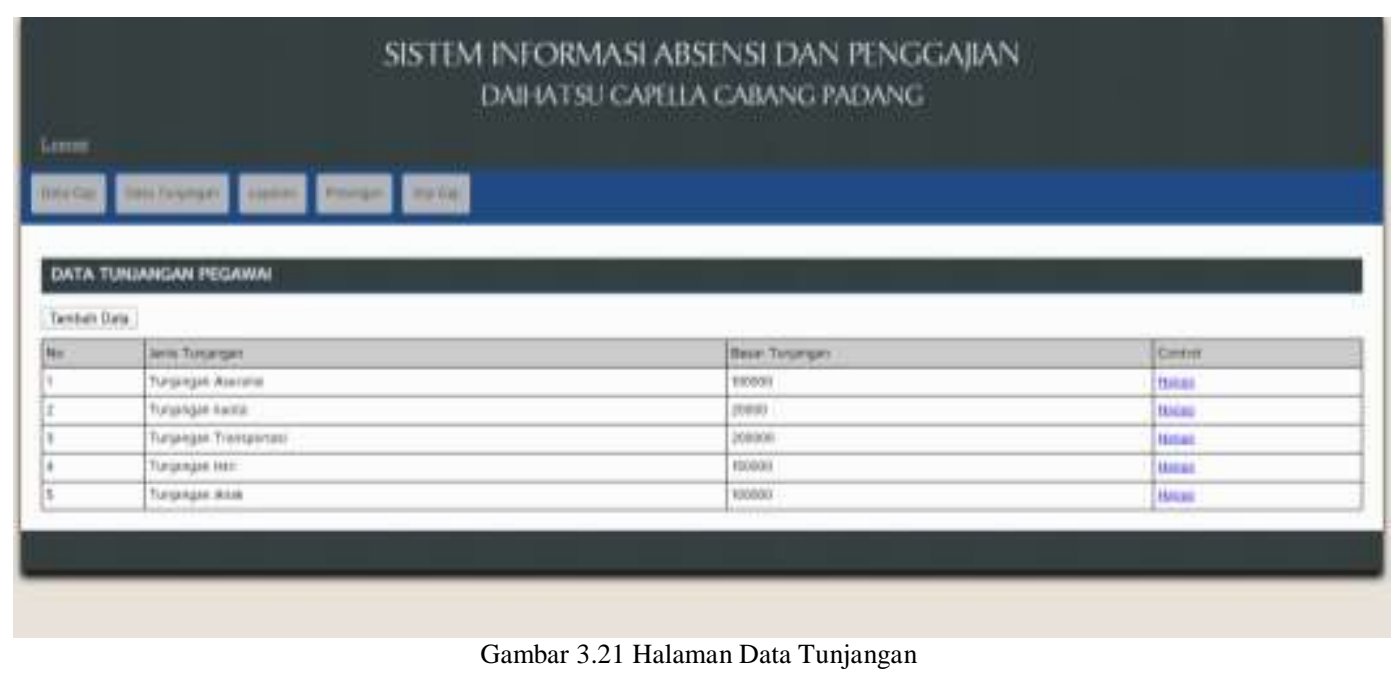

20. Halaman Potongan

Halaman Potongan berisikan data potongan untuk karyawan, dapat dilihat gambar 3.22 berikut ini :

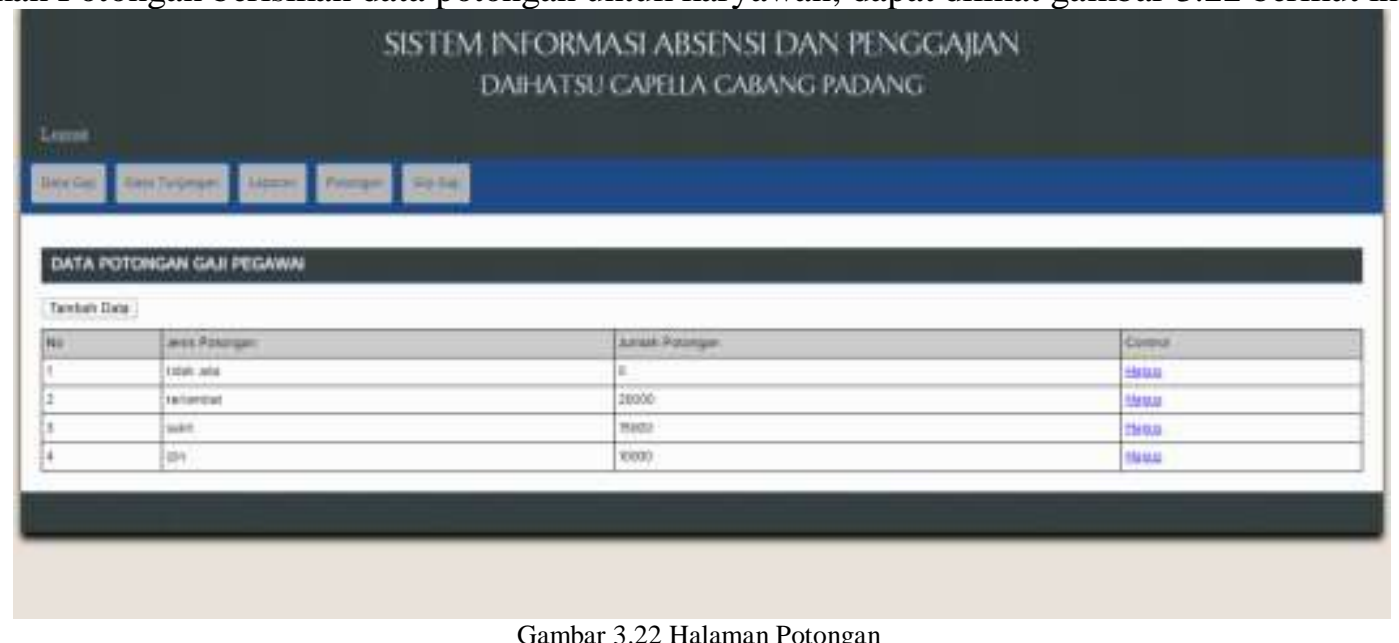

Gambar 3.22 Halaman Potongan 


\section{Halaman Slip Gaji}

Halaman Slip Gaji berisikan data slip gaji untuk karyawan, dapat dilihat gambar 3.23 berikut ini :

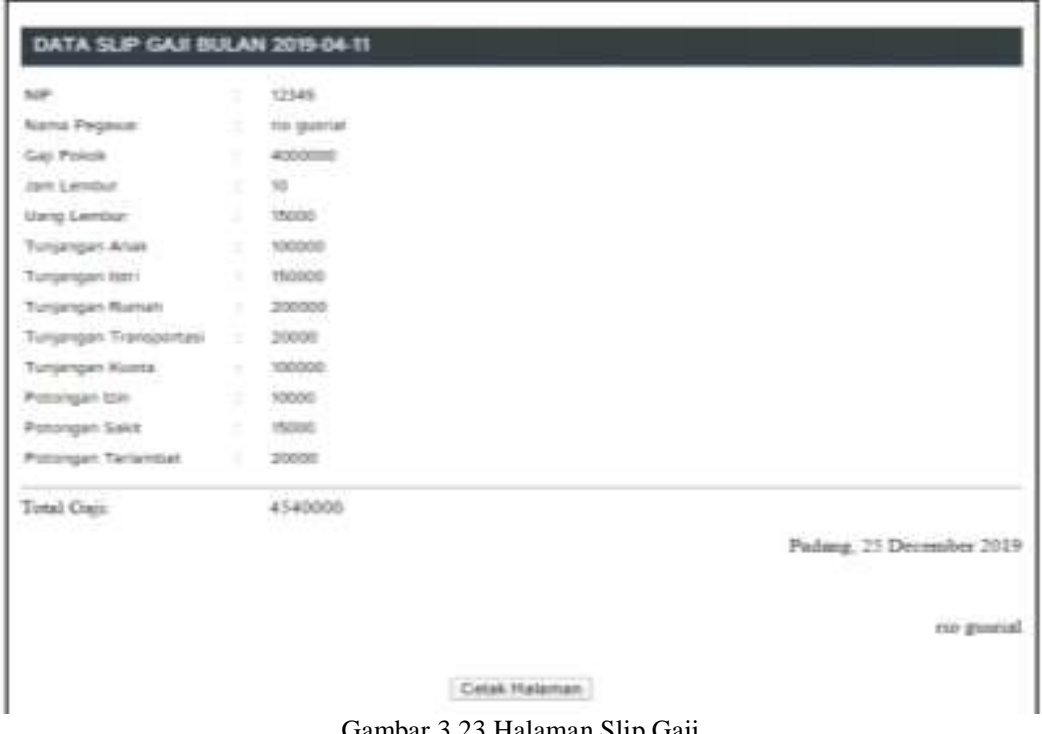

Gambar 3.23 Halaman Slip Gaji

\section{Kesimpulan}

Berdasarkan hasil pembahasan yang telah dilakukan pada bab-bab sebelumnya, maka penulis mengambil beberapa kesimpulan dari pembuatan sistem informasi absensi dan penggajian karyawan yaitu:

1. Diharapkan rancangan aplikasi pengelolaan data absensi dan penggajian karyawan dapat membantu dalam mengolah data.

2 Diharapkan rancangan aplikasi pengelolaan absensi dan penggajian karyawan pada DAIHATSU CAPELLA MEDAN CABANG PADANG menggunakan bahasa pemrograman PHP MySql dapat menyimpan data absensi dan gaji karyawan dengan baik dan akurat.

3 Diharapkan sistem ini mampu mengimplementasikan data absensi dan penggajian karyawan untuk dapat membantu proses absensi dan penggajian karyawan berjalan dengan efektif dan efisien.

\section{DAFTAR PUSTAKA}

[1] A.S, Rosa dan M.Salahiddin, 2014. Rekayasa Perangkat Lunak Terstruktur Dan Berorientasi Objek, Bandung : Informatika.

[2] Ade Handini. 2016. PEMODELAN UML SISTEM INFORMASI MONITORING PENJUALAN DAN STOK BARANG (STUDI KASUS: DISTRO ZHEZHA PONTIANAK). Program Studi Manajemen Informatika AMIK "BSI Pontianak"

[3] Ananta, Priranda Widara dan Sri Winiarti, 2013. Sistem Pendukung Keputusan Dalam Penilaian Kinerja Pegawai Untuk Kenaikan Jabatan Pegawai Menggunakan Metode Gap Kompetensi (Studi Kasus Perusahaan Perkasa Jaya Compuretail). Jurnal Sarjana Teknik Informatika, Volume 1 Nomor 2, Hal 574-583.

[4] Hj.Ria Ratna Ariwati.2016.Riset Akuntansi,Vol III,No 2, ISSN 2086-0.

[5] Aprianti, Winda, Umi Maliha, 2016. Sistem Informasi Kepadatan Penduduk Kelurahan Atau Desa Studi Kasus Pada Kecamatan BatiBati Kabupaten Tanah Laut, Jurnal Sains dan Informatika, Vol 2, Nomor 1, Hal. 21-28.

[6] Al-Rosyid, Harun, Bambang Eka Purnama dan Indah Uly Wardati, 2015. Sistem Informasi Penjualan Buku Berbasis Website Pada Toko Buku Standard Book Seller Pacitan, Journal On Networking And Security, Vol. 1, No. 1, Hal. 1-6.

[7] Agus, I Putu Eka Pratama, 2014. Sistem Informasi Dan Implementasi, Bandung : Informatika.

[8] Dika Nurul Handayani. 2014. Mengenal Web Hosting. ILMUTI : Ilmu Teknologi Informasi

[9] Eniyati, S. 2011. "Perancangan Sistem Pendukung Pengambilan Keputusan untuk Penerimaan Beasiswa dengan Metode SAW (Simple Additive Weighting)". Jurnal Teknologi Informasi DINAMIK. 16(2), 171-177.

[10] Eniyati, S. dan Noor Santi, R.C. 2010. "Perancangan Sistem Pendukung Keputusan Penilaian Prestasi Dosen Berdasarkan Penelitian dan Pengabdian Masyarakat”. Jurnal Teknologi Informasi DINAMIK. 15(2), 136-142.

[11] Fitrianti, Uli dan Mutammimul Ula, 2016. Implementasi Algoritma Levenshtein Distance Dan Algoritma Knuth Morris Pratt Pada Aplikasi Asmaul Husna Berbasis Android, Jurnal Sistem Informasi, Vol. 1, No. 1, Hal. 25-60.

[12] Handojo, A. Setiabudi, D.H. danYunita, R. 2003. "Pembuatan Aplikasi Sistem Pendukung Keputusan Untuk Proses Kenaikan Jabatan dan Perencanaan Karirpada PT. X”. Jurnal Informatika. 4(2), 98-106.

[13] Hepyan, C.L. Gunadhi, E. danKurniawati, R. 2012. "Rekayasa Perangkat Lunak Aplikasi Penjualan Obat pada Apotek Mulya Abadi”. Jurnal Algoritma. 9, 1-11. 
[14] Iswandy, Eka, 2015. Sistem Penunjang Keputusan Untuk Menentukan Penerimaan Dana Santunan Sosial Anak Nagari Dan Penyalurannya Bagi Mahasiswa Dan Pelajar Kurang Mampu Di Kenagarian Barung - Barung Balantai Timur, Jurnal TEKNOIF, Vol. 3 No. 2, Hal. 71-79.

[15] Kusrini. 2007. Konsepdan Aplikasi Sistem Pendukung Keputusan. Yogyakarta: ANDI.

[16] Muqtadir, Asfan dan Irwan Purdianto, 2013. Sistem Pendukung Keputusan Kenaikan Jabatan Menggunakan Metode Profile Matching (Studi Kasus di PT. Industri Kemasan Semen Gresik), Seminar Nasional Aplikasi Teknologi Informasi (SNATI), Vol. 1, No. 1, Hal. E48-E55.

[17] Perdhana, A.S. Laksito, W.Y.S. danSiswanti, S. 2013. "Sistem Pendukung Keputusan Pemilihan Jenis Laptop Dengan Menggunakan Metode Analytical Hierarchy Process". 1(1), 53-59.

[18] Gusman, A. P. (2019). ANALISA PERANCANGAN DAN IMPLEMENTASI PEMESANAN SECARA ONLINE BERBASIS COSTUMER RELATIONSHIP MANAGEMENT (CRM). MAJALAH ILMIAH, 26(1), 7-13. 